\title{
Development of anti-immunocomplex specific antibodies and non-competitive time-resolved fluorescence immunoassay for the detection of estradiol
}

\author{
Janne Leivo $^{1} \cdot$ Laura Kivimäki $^{1,2} \cdot$ Etvi Juntunen ${ }^{1,3} \cdot$ Kim Pettersson $^{1} \cdot$ Urpo Lamminmäki $^{1}$
}

Received: 26 March 2019 / Revised: 7 May 2019 / Accepted: 28 May 2019 / Published online: 8 June 2019

(C) The Author(s) 2019

\begin{abstract}
Detection of circulatory estradiol has widespread use in various clinical applications. Particularly, the use of estradiol-specific antibodies in immunoassays is routinely used, mainly due to the cost efficiency and simplicity of the sample handling process. However, the circulatory levels of estradiol can be extremely low in some conditions, and beyond the current detection limit of existing competitive immunoassays. We describe the generation of anti-immunocomplex specific antibodies derived from synthetic antibody repertoire and the development of high-performance non-competitive immunoassay for the detection of estradiol. Phage display selections were used to isolate new antibodies from synthetic antibody library with the use of existing estradiol specific Fab fragment. The found antibodies were consecutively used to set up a time-resolved fluorescence-based immunoassay (TRFIA), which can be used to detect estradiol with exceptional sensitivity and specificity. The limit of detection and EC50 were shown to be $3.0 \mathrm{pg} \mathrm{mL}^{-1}$ and $32.4 \mathrm{pg} \mathrm{mL}^{-1}$ respectively.
\end{abstract}

Keywords Antibody $\cdot$ Immunoassay $\cdot$ Phage display $\cdot$ Antibody engineering $\cdot$ Estradiol

\section{Introduction}

Monitoring the levels of estrogenic hormones in circulation can provide pleiotropic information, useful in the evaluation of gonadal functionality related to infertility, menopausal state or male feminization. Particular interest in clinical diagnostics and research has gained the measurement of estradiol (E2), the most potent of the naturally occurring estrogenic hormones [1]. The accurate measurement of $\mathrm{E} 2$ in clinical setting is hampered by the very broad range of circulatory levels, ranging from < $20 \mathrm{pg} \mathrm{mL}^{-1}$ in prepubertal children to $>10,000 \mathrm{pg} \mathrm{mL}^{-1}$ during pregnancy and ovarian stimulation treatment [2]. Furthermore, the clinically relevant information extracted from the circulatory E2 levels for example during aromatase inhibitor therapy for

Janne Leivo

jpleiv@utu.fi

1 Department of Biochemistry, University of Turku, Kiinanmyllynkatu 10, 20520 Turku, Finland

2 Labmaster Oy, Fiskarsinkatu 11, 20750 Turku, Finland

3 Inme Ltd, Itäinen pitkäkatu 4B, 20520 Turku, Finland breast cancer requires high-performance detection methods with adequate sensitivity [3]. Besides sensitivity, the routine measurement of E2 often requires rapid and economical solutions to process large samples quantities efficiently.

The most established method for the measurement of E2 from biofluids is based on chromatographic separation of E2, often combined with mass-spectrometric (MS) analysis [4]. More recently, technological advancements have simplified this analytical process; particularly, the combination of HPLC and tandem MS has gained increasing focus $[5,6]$. Such methods which are based on the physical separation of the target analyte require specialized instrumentation and are not suitable for high-throughput screening. Furthermore, the possibility to measure $\mathrm{E} 2$ levels from unprocessed biofluids in a more simple, decentralized manner is often preferred.

Immunoassays for the measurement of E2 have been in routine clinical use since the late 1960s [7]. Although the immunoassays for the measurement of circulatory E2 have evolved both in terms of detection limit and specificity, the issues related to the poor sensitivity and reproducibility make existing assays invalid for epidemiologic studies $[8,9]$. Majority of the commercially available immunoassays for the detection of E2 are based on competition of the free and 
labelled E2. As the sensitivity of the competitive assays is intrinsically dependent on the amount of available binding sites, these assays are more prone to interferences caused by matrix effects and cross-reactive compounds. In addition, the sensitivity of competitive immunoassays is often lower in comparison with the non-competitive equivalent and is unsuitable for the measurement of samples containing low E2 levels $\left(<40 \mathrm{pg} \mathrm{mL}^{-1}\right)$. Although the benefits of using noncompetitive format to set up new assays for E2 detection are evident, the development of such assays is challenging due to the extremely small size of the analyte. For example, the traditional sandwich-type immunoassay, which utilizes the binding of two different antibodies against the same target, is not possible due to the limited amount of available epitopes on E2. This limitation can be circumvented in some cases with the use of immunocomplex specific antibodies [10]. There has been a steady increase in studies describing the use of immunocomplex antibodies for the detection of lowmolecular-weight compounds [11, 12].

One of the main limitations for more widespread use of anti-immunocomplex specific antibodies is the tedious antibody development process, which can be very challenging with traditional methods based on the immunization of animals [13]. With the introduction of in vitro antibody development methods, the selection conditions throughout the antibody development process can be controlled more efficiently enabling the generation of antibodies with predefined specificity to complex targets. Phage display has been used to create immunocomplex specific binders against small analytes such as morphine [14], mycotoxins [15], and cyanotoxins [11]. In comparison with conventional competitive immunoassays, the use of immunocomplex assays has multiple benefits. (1) Since the interaction is based on the binding of the two antibodies, there is no need for a chemically conjugated or labelled analyte for the detection. (2) The intrinsically noncompetitive format results in enhanced binding kinetics, assay sensitivity, and linear range. (3) Versatility on the design of assay concept results from the use of two antibodies in the assay setup. In addition to the use in conventional noncompetitive ELISA, immunocomplex-based assays have been successfully implemented in homogenous formats utilizing advanced reporter technologies such as TR-FRET [12].

We describe the generation of anti-immunocomplex specific antibodies derived from synthetic antibody library. The found antibodies were utilized in the development of a noncompetitive immunocomplex immunoassay which can detect E2 with high sensitivity. The detection is based on the binding of the secondary antibody in the presence of both primary S16-Fab and soluble E2 (Fig. 1). The half-maximal effective concentration (EC50) and limit of detection (LoD) were $32.4 \mathrm{pg} \mathrm{mL}^{-1}$ and $3.0 \mathrm{pg} \mathrm{mL}^{-1}$ respectively, indicating sufficient performance for the measurement of samples containing very low levels of circulatory E2.

\section{Materials and methods}

\section{Materials and reagents}

For the immunoassays, DELFIA series buffers and streptavidin-coated 96-well microtiter plates were purchased from Kaivogen Diagnostics (Turku, Finland). All measurements were done with Victor 1420 fluorometer from PerkinElmer (Turku, Finland). Magnetic nanoparticles and magnetic bead concentrator and hyperphages were from Invitrogen (Thermo, USA). The hormones used in this study, $17 \beta$ estradiol estrone, estriol, and $17 \beta$-estradiol-3-glucoronide, were from Sigma-Aldrich (USA). The E. coli cell lines used for the sorting and expression of the antibody libraries were purchased from Stratagene (USA): BL21 (F-, dcm, ompT,

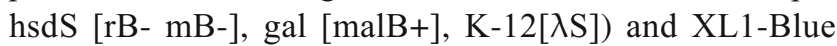
(recA1, endA1, gyrA96, thi-1, hsdR17, relA1, lac [F', TetR]). All microbiological reagents were prepared as described in Sambrook et al. [16]. The single-chain alkaline phosphatase ( $\mathrm{scFv}$-BALP) fusion proteins were purified with Ni-NTA (Thermo Scientific, USA). The ELISA substrate para-nitrophenylphosphate (pNPP) and activated charcoal used for the depletion of hormones from the serum samples were obtained from Sigma-Aldrich (USA).

\section{Standard solutions and samples}

The E2 standard solutions were done in absolute ethanol $(\mathrm{EtOH})$. The primary stock was done by dissolving E2 in $\mathrm{EtOH}$ in the concentration of $20 \mathrm{mM}$. For the assays, the working concentrations were established in the range of $0.1-$ $10,000 \mathrm{pM}$. For the analysis of sample matrix interference, the standard concentrations were set in the range of $6.25-150 \mathrm{pM}$. The serum samples used to study the matrix effects were obtained from healthy young male volunteers.

\section{Antibody development}

Previously well characterized anti-E2 S16 Fab was used for the capture of E2 in both phage display selections and immunoassays [17]. For the development of the secondary antibody specific to the immunocomplex, synthetic antibody libraries and phage display were used, described in previous studies by Brockmann et al. [18] and Huovinen et al. [19]. The pEB32x phagemid vector used for the phage display selections was designed to contain a trypsin cut-site between the antibody fragment and the truncated pVIII phage coat protein. The phage display selections were carried out with following conditions: S16 Fab $(8 \mu \mathrm{g})$ which was covalently coupled to Tosyl-activated paramagnetic beads (Dynal, Norway) supplemented with E2 $(10 \mu \mathrm{M})$ for $1 \mathrm{~h}$ in rotation. The beads were washed three times with TBT-0.1 $(50 \mathrm{mM}$ Tris, $150 \mathrm{mM}$ $\mathrm{NaCl}, 1 \%$ BSA-fraction $\mathrm{V}, 0.1 \%$ Tween-20, $\mathrm{pH} 7.5$ ) buffer 
Fig. 1 The concept of an immunocomplex assay. a In the absence of free E2, the C6 scFvBALP antibody does not interact with the immobilized S16-Fab. b The formation of immunocomplex is dependent on the interaction of E2 to the binding site of the S16 Fab

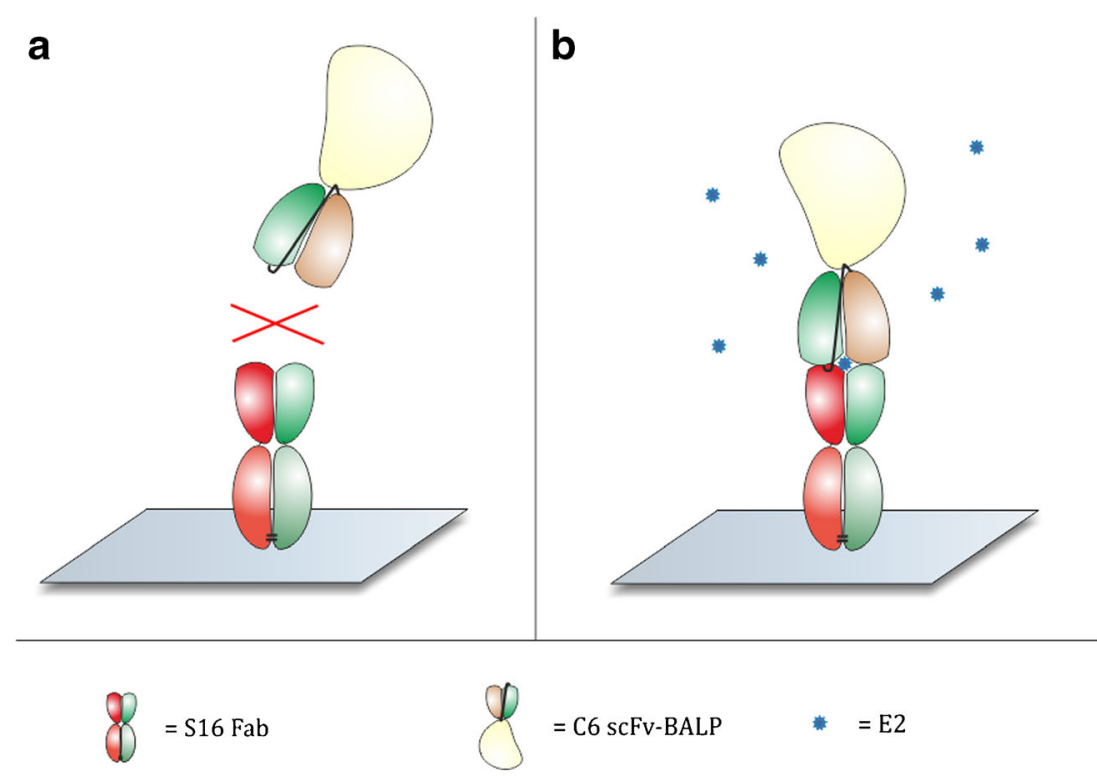

and $1 \times 10^{12}$ tfu of library phages was mixed with beads. The step was supplemented with unspecific mouse $\operatorname{IgG}(100 \mu \mathrm{g})$ to deplete the antibodies recognizing regions not involved in the antigen binding. The solution was incubated for $2 \mathrm{~h}$ at room temperature (RT). The beads were washed three times with TBT- 0.1 buffer and once with TSAT (50 mM Tris, $150 \mathrm{mM}$ $\mathrm{NaCl}, 0.05 \%$ Tween-20, $\mathrm{pH} 7.5$ ) before elution with $10 \mu \mathrm{g} / \mathrm{ml}$ of trypsin for $30 \mathrm{~min}$ at RT. The eluate was used to infect XL1Blue cells in exponential growth phase. The phages were repropagated from the cells collected from the output plate as described previously. For the second and third rounds of phage display selections, the beads were changed to Dynabeads M280 (0.1 mg) which were coated with biotinylated-S16 Fab (bio-S16 Fab). The amounts of S16 Fab, E2, and phages were reduced after each selections round to increase the selection stringency.

Antibody screening and characterization For the screening, the antibody gene pool from the third selection round was cloned to $\mathrm{pLK} 06 \mathrm{H}$ expression vector to enable the production of the scFv fragment in fusion with bacterial alkaline phosphatase (BALP). Individual colonies $(n=190)$ were screened from the transformation plate and cultured on a 96-well tissue microtiter plate in $150 \mu \mathrm{L}$ volume of SB supplemented with $100 \mu \mathrm{g} / \mathrm{ml}$ of ampicillin, $10 \mu \mathrm{g} / \mathrm{ml}$ tetracycline, and $0.05 \%$ glucose. The scFv-BALP production was induced with $250 \mu \mathrm{M}$ IPTG. The overnight production of the scFv-BALP was done in plate shaker with $900 \mathrm{rpm}$ at $+26^{\circ} \mathrm{C}$. The cells were removed with $6800 \mathrm{~g}$ centrifugation for $30 \mathrm{~min}$ at $+4{ }^{\circ} \mathrm{C}$ and $10 \mu \mathrm{L}$ of the culture supernatant was used in the primary screening immunoassay. For the more detailed characterization, the antibodies were produced in $400 \mathrm{ml}$ culture of $\mathrm{Bl} / 21$ cells and consecutively purified as described previously [20].

\section{Immunoassays}

Phage preparations isolated after each selection round were used in an immunoreactivity assay, where the enrichment of the immunocomplex specific phages was monitored with the use of TRF immunoassay using the following conditions. The S16-Fab (100 ng) was immobilized on streptavidin-coated microtiter wells for $1 \mathrm{~h}$. After four washes, E2 (50 nM) and repropagated phages from each selection round $\left(1 \times 10^{8} \mathrm{tfu}\right)$ were added to the wells and incubated for $2 \mathrm{~h}$. The wells were washed twice before the addition of europium-labelled anti-fd IgG.

The screening of the scFv-BALP antibodies was done in two phases: the primary screening was done with single colony screening from the culture supernatant of the 96-well plate. The screening assay was used to determine the signal differences from two wells containing the S16-Fab (100 ng) with and without E2 (50 nM). The most promising clones were selected for further characterization in secondary screening assay, where 100-ng bio-S16 Fab was used to capture E2 with five different concentrations $(10,30,100,300$, $1000 \mathrm{pM})$.

The selectivity of the parental S16-Fab has been previously shown to be very specific to E2 with low cross-reactivity for other estrogenic compounds. To confirm this, we analyzed the cross-reactivity of the assay against three estrogens: estrone (E1), estriol (E3), and estradiol-3-glucoronide (E2-gluc), which were added in three concentration $(15,50$, and $100 \mathrm{nM}$ ) to the immunoassay.

After optimization steps, the assay condition was set as follows: the streptavidin wells were coated with $5 \mathrm{ng}$ of bio-S16 Fab and incubated for $1 \mathrm{~h}$. After four washes, serial dilutions, ranging from $0.1-10,000 \mathrm{pg} \mathrm{L}^{-1}$, of E2 
Fig. 2 a The primary screening for the immunocomplex antibodies was done in 96-well plates where the binding of the clones was distinguished between signal differences of two wells containing the S16-Fab with and without E2 (50 nM). The heatmap shows the specific signal of absorbance measured at $405 \mathrm{~nm}$. b Seven of the most promising clones were selected for further characterization with an ELISA consisting of five concentration points of E2, the EC50 values; the error bars represent the standard error of the EC50. c The immunoreactivity of the phage stocks after each phage display selection round. The error bars represent the standard deviation of three replicate measurements
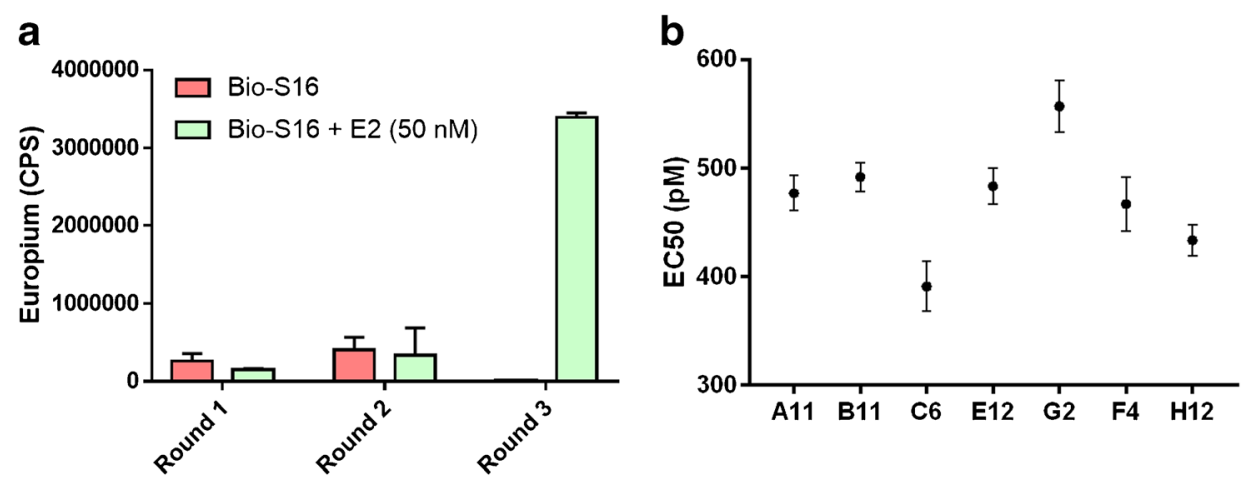

C $\begin{array}{llllllllllll}1 & 2 & 3 & 4 & 5 & 6 & 7 & 8 & 9 & 10 & 11 & 12\end{array}$ 1 $\begin{array}{lllll}2 & 3 & 4 & 5 & 6\end{array}$
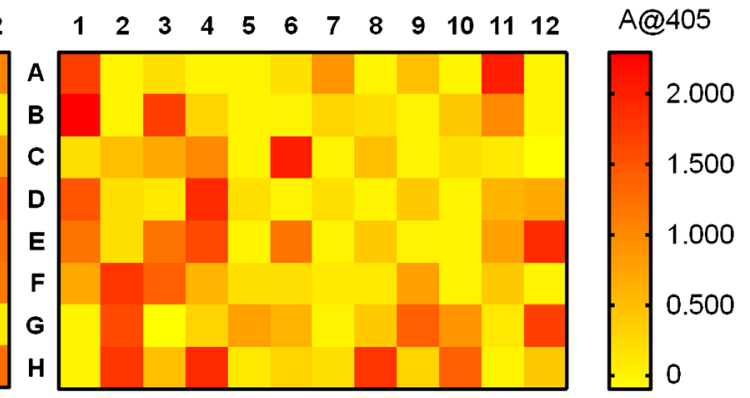

were added to the wells as triplicates for each concentration point. For detection, C6 scFv-BALP antibody (10 ng) and Eu-labelled anti-BALP antibody (15 ng) were added to each well and the plates were incubated for $2 \mathrm{~h}$. The wells were washed four times before the addition of DELFIA enhancement solution. After 15-min incubation, the TRF europium signal was measured.

To study the matrix effect of serum in the immunocomplex assay, serum was collected from three healthy male donors with written consent from the lab members of the Biotechnology Division, University of Turku. The hormones were stripped from the serum with the use of $0.1 \%$ activated charcoal. The charcoal was removed from the samples with centrifugation at $132,000 \mathrm{~g}$ for $15 \mathrm{~min}$, followed by a filtration with $0.22-\mu \mathrm{m}$ filter. For the immunoassay, variable amounts

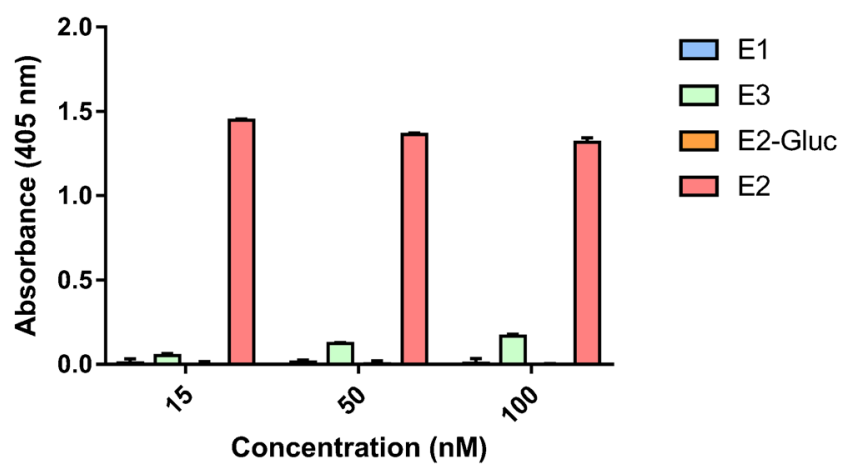

Fig. 3 Selectivity of the immunoassay as analyzed with the use of four different estrogens (E1, E3 E2-gluc, and E2). Each estrogen was added in three concentrations $(25,50$, and $100 \mathrm{nM})$. The error bars show the standard deviation of three replicate measurements of E2 ranging between 6.25 and $150 \mathrm{pM}$ were spiked to samples to analyze the matrix effect. A 1:10 dilution of the serum sample was used for the determination of the recovery capability of the immunoassay.

\section{Data management}

The graphs for the assay performance and determination of the EC50 values and $R^{2}$ were done with the use of GraphPad Prism (GraphPad Software Inc.). The general analytical parameters $\mathrm{LoD}$ and $\mathrm{LoQ}$ were calculated from the mean of the background $+3 \times \mathrm{SD}(\mathrm{LoD})$ and $10 \times \mathrm{SD}(\mathrm{LoQ})$. The intraand interassay imprecision was determined from the mean of CV\% with the use of E2 spiked in three concentrations (25, $50,100 \mathrm{pM})$ to pooled serum samples $(n=3)$, which were analyzed in two consecutive days.

\section{Results and discussion}

\section{Antibody development and characterization}

In this study, we used previously established synthetic antibody libraries, and a high-affinity recombinant Fab fragment specific to E2 as a source of immunocomplex specific binders. The synthetic antibody libraries were constructed on the basis of phage display selections, which provides greater control over the various parameters of the antibody selection process in comparison with immunization-based antibody generation strategies. To direct the phage display selection pressure 
a

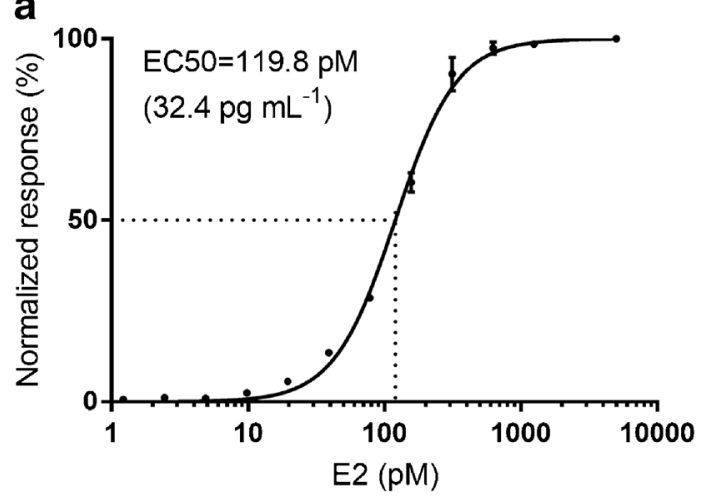

Fig. 4 Assay performance with optimized conditions. a Standard curve for the detection was done on the basis of 12 concentration points of E2 ranging between 0.1 and $10,000 \mathrm{pg} \mathrm{L}-1$. The error bars indicate the SD of

towards the antigen-binding regions of S16-Fab complexed with E2, we used both intact mouse IgG and unconjugated S16-Fab to deplete the unspecific binders prior to the introduction of the target immunocomplex. In addition, the overall stringency of the selections was increased throughout the selection rounds, both with the use of additional washing cycles and with the reduction of the amount of S16-Fab and E2 used for the immobilization. Based on the number of colonies on the output plates obtained after each selection round, and the immunoreactivity assay done to the phage stocks, a strong immunocomplex specific enrichment was observed after three selection rounds in the presence of $50 \mathrm{nM}$ of E2 (Fig. 2a). In the third round phage pool, there was no detectable binding against the S16-Fab without soluble E2 in the immunoreactivity TRFIA, indicating a successful depletion of the phages specific to the regions not involved in the binding of E2.

The primary single colony screening of individual $\mathrm{scFv}$ BALP antibodies was done with conventional ELISA utilizing the catalytic activity of the BALP in the presence of pNPP. From the 190 colonies screened, 26 clones were above the threshold set for the assay (signal/background level $>5$ ), and seven were selected for further characterization (Fig. 2b, c).

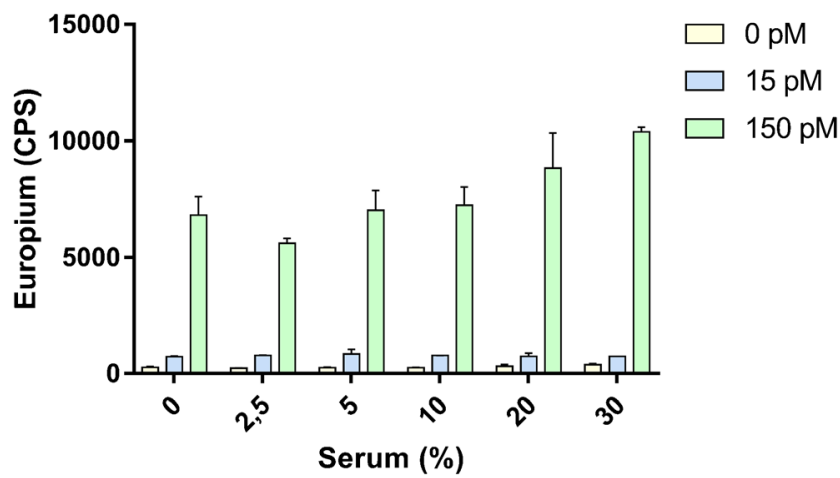

Fig. 5 Matrix effect on the TRFIA. The effect of increasing amounts of serum, ranging between 2.5 and $30 \%$, on the assay was assessed using two concentration points of E2 ( 15 and $150 \mathrm{pM})$. The error bars represent the SD of the europium signal

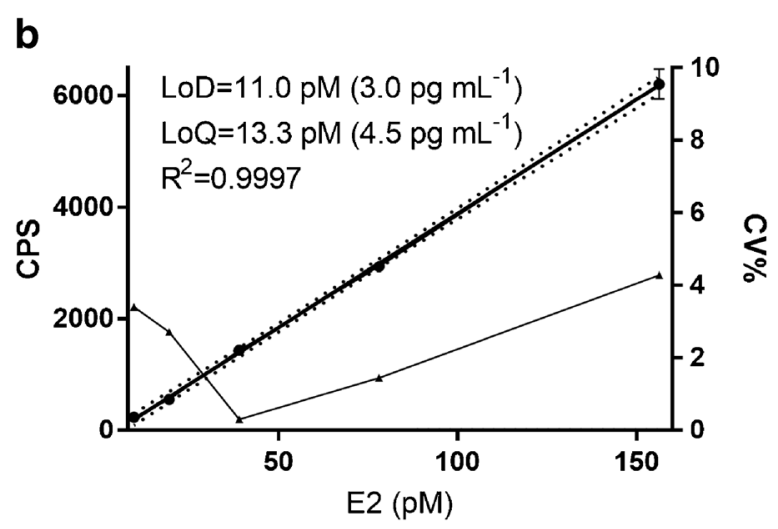

three replicate measurements. b Limit of detection and limit of quantification were calculated from the mean of the background $+3 \times$ SD and $10 \times$ SD respectively

Based on the secondary screening done with immunoassay consisting of increasing E2 concentrations, all seven clones were specific for the S16 Fab-E2 complex with EC50 values below $1 \mathrm{nM}$ (Fig. 2b). The most promising clone with lowest EC50 values, $\mathrm{C} 6 \mathrm{scFv}$-BALP, was produced in larger quantities and subjected to further characterization and assay development.

\section{TRF immunoassay development and optimization}

The binding characteristics of the S16-Fab were previously shown to bind E2 with high affinity $(0.27 \mathrm{nM})$ and specificity, establishing a good starting point for the development of a non-competitive immunocomplex assay [17]. The selectivity of the found $\mathrm{C} 6 \mathrm{scFv}$ was analyzed with the use of different estrogens (E1, E3, and E2-gluc) in comparison with E2 (Fig. 3). No observable reactivity could be detected for estrone. For the structurally similar E2-3-glucuronide, which has caused cross-reactivity issues to the parental E2-specific antibodies, the assay did not show any reactivity. The only compound tested which caused interference in the assay was estriol especially at

Table 1 Recovery of E2 from spiked serum samples. Three charcoalstripped serum samples were used to assess the recovery capability of the E2 immunoassay. The serum samples were spiked with five concentrations of E2 in three different healthy males

\begin{tabular}{|c|c|c|c|c|c|c|}
\hline \multirow[t]{3}{*}{ Spiked (pM) } & \multicolumn{6}{|l|}{ Serum } \\
\hline & \multicolumn{2}{|l|}{ S1 } & \multicolumn{2}{|l|}{$\mathrm{S} 2$} & \multicolumn{2}{|l|}{ S3 } \\
\hline & Found & $\mathrm{CV} \%$ & Found & $\mathrm{CV} \%$ & Found & CV\% \\
\hline 6.25 & 9.5 & 1.5 & 8.4 & 6.4 & 10.5 & 8.5 \\
\hline 12.5 & 15.1 & 0.7 & 14.7 & 0.4 & 15.6 & 2.2 \\
\hline 25 & 25.3 & 2.0 & 27.3 & 5.5 & 25.7 & 4.1 \\
\hline 50 & 42.8 & 9.6 & 52.3 & 1.9 & 43.6 & 4.5 \\
\hline 100 & 92.5 & 8.4 & 105.8 & 14.2 & 81.7 & 3.6 \\
\hline
\end{tabular}


Table 2 Intraassay, interassay, and total imprecision of the immunoassay in pooled serum samples at three E2 concentrations

\begin{tabular}{llll}
\hline E2 concentration $(\mathrm{pM})$ & $\mathrm{CV} \%$ & & \\
\cline { 2 - 4 } & Intraassay $(n=3)$ & Interassay $(n=3 \times 2)$ & Total \\
\hline 25 & 6.7 & 4.9 & 11.5 \\
50 & 2.6 & 4.0 & 6.6 \\
100 & 4.1 & 4.4 & 8.5 \\
\hline
\end{tabular}

higher concentration (>100 nM). However, for clinical use, this most likely will not be an issue considering the very low levels of circulatory E3 in non-pregnant women. Moreover, the selectivity of the assay clearly was towards $\mathrm{E} 2$, as the EC50 values could not be determined for none of the other estrogenic compounds.

Prior to the full characterization of the $\mathrm{C} 6 \mathrm{scFv}$-BALP binding properties, the antibody was produced in a larger scale and purified. The assay optimization was started by adjusting the general parameters, such as incubation time, buffer $\mathrm{pH}$, antibody concentrations and amount of washes, prior to the analysis of final assay performance (results not shown). Although the initial screening and characterization of the scFv-BALP antibodies were done in ELISA format, the TRFIA-based reporter was used in the final assay setup for enhanced sensitivity.

\section{Assay performance}

For the determination of half-maximal effective concentration (EC50), 12 concentration points of E2 ranging between 0.1 and $10,000 \mathrm{pg} \mathrm{L}^{-1}$ were used (Fig. 4). The EC50 for optimized assay was found to be $119 \mathrm{pM}\left(32.4 \mathrm{pg} \mathrm{mL}^{-1}\right)$, with a limit of detection (LoD) of $11 \mathrm{pM}\left(3.0 \mathrm{pg} \mathrm{mL}^{-1}\right)$ and limit of quantification (LoQ) of $13.3 \mathrm{pM}\left(4.5 \mathrm{pg} \mathrm{mL}^{-1}\right)$. These values suggest promise for the detection of low-range concentrations of $\mathrm{E} 2$, which is currently the most problematic sample group for existing E2 assays [21, 22].

The optimal conditions for the final immunocomplex assay were used to characterize the more specific parameters of the assay. First, we determined the significance of the matrix effect on the antibody interaction with the use of charcoalstripped serum samples pooled from three donors. The addition of serum to the immunoassay had only minor effect on the signal levels of the assay as shown in Fig. 5. For the matrix effect tests, the serum was stripped of free hormones to reduce the effect of soluble E2. The removal of E2 clearly was not complete as can be observed in Fig. 5, where a slight, but significant, increase in signal can be observed with the increasing amount of serum added to the well. The overall interference caused by the use of serum as a sample matrix was minimal with acceptable variability. Next, we spiked variable amounts of E2 to three individual charcoal-stripped serum samples obtained from healthy volunteers (Table 1). The recoveries ranged between 82 and $167 \%$ with acceptable CV\%. Higher recoveries were observed in lower E2 concentration, which is a well-known source for error when approaching the detection limit of the immunoassay. Next, the imprecision of the assay was evaluated by analyzing three pools of serum samples in triplicate in two consecutive days (Table 2). Overall, the imprecision remained acceptable along the different concentration points of E2 measured. Apart from the lowest E2 concentration ( $25 \mathrm{pM})$, the imprecision of the system remained below $10 \%$. Although the assay described in this study was optimized for the detection of E2 from serum samples, similar approach can be used in the future for the analysis of E2 from less complex matrices, such as urine and waste water.

Immunocomplex-based assays against E2 and other small molecules enable the development of versatile assay setups for the detection and screening of the respective compounds. The non-competitive assay format overperforms the competitive counterparts in the most crucial aspects of a reliable immunoassay. In addition, the described assay setup which consists of two recombinant antibodies can be easily converted into homogeneous format utilizing advanced reporter technologies such as TRFRET [23] and upconverting phosphors (UCP) [24]. Most widely used application for the detection of E2 is mainly done in the clinic; during the assessment of gonadal activity, applications for E2 monitoring can be found also in environmental and veterinary diagnostics $[25,26]$. Although the assay described in this study needs to be validated with a larger sample set, where the E2 values have been established with a reference method, our assay demonstrates potential in the detection of very low E2 concentrations from unextracted serum samples. The assay demonstrates high performance in terms of analytical sensitivity, and with further optimization or engineering the binding properties of the $\mathrm{C} 6-\mathrm{scFv}$ antibody, it is possible to establish new tools for the detection of E2 concentrations ranging between 0.2 and $2 \mathrm{pg} \mathrm{mL}^{-1}$, which currently is lacking reliable and accurate methods.

Acknowledgements Open access funding provided by University of Turku (UTU) including Turku University Central Hospital.

\section{Compliance with ethical standards}

The serum samples used for this study were collected with informed consent from healthy volunteers of the lab members of Biotechnology Division, University of Turku. The study was conducted in compliance with the ethical permission for this study which was obtained from the University of Turku ethics committee (statement number 56/2018). 
Conflict of interest The authors declare that there are no conflicts of interest.

Open Access This article is distributed under the terms of the Creative Commons Attribution 4.0 International License (http:// creativecommons.org/licenses/by/4.0/), which permits unrestricted use, distribution, and reproduction in any medium, provided you give appropriate credit to the original author(s) and the source, provide a link to the Creative Commons license, and indicate if changes were made.

\section{References}

1. Adashi EY. Endocrinology of the ovary. Hum Reprod. 1994;9:815-27.

2. Rosner W, Hankinson SE, Sluss PM, Vesper HW, Wierman ME. Challenges to the measurement of estradiol: an endocrine society position statement. J Clin Endocr Metab. 2013;98:1376-87.

3. Santen RJ, Demers L, Ohorodnik S, Settlage J, Langecker P, Blanchett D, et al. Superiority of gas chromatography/tandem mass spectrometry assay (GC/MS/MS) for estradiol for monitoring of aromatase inhibitor therapy. Steroids. 2007;72:666-71.

4. Kushnir MM, Rockwood AL, Bergquist J, Varshavsky M, Roberts WL, Yue B, et al. High-sensitivity tandem mass spectrometry assay for serum estrone and estradiol. Am J Clin Pathol. 2008;129:530-9.

5. Keski-Rahkonen P, Huhtinen K, Desai R, Tim Harwood D, Handelsman DJ, Poutanen M, et al. LC-MS analysis of estradiol in human serum and endometrial tissue: comparison of electrospray ionization, atmospheric pressure chemical ionization and atmospheric pressure photoionization. J Mass Spectrom. 2013;48: 1050-8.

6. Harwood DT, Handelsman DJ. Development and validation of a sensitive liquid chromatography-tandem mass spectrometry assay to simultaneously measure androgens and estrogens in serum without derivatization. Clin Chim Acta. 2009;409:78-84.

7. Abraham GE. Solid-phase radioimmunoassay of estradiol-17 $\beta$. J Clin Endocr Metab. 1969;29:866-70.

8. Yang DT, Owen WE, Ramsay CS, Xie H, Roberts WL. Performance characteristics of eight estradiol immunoassays. Am J Clin Pathol. 2004;122:332-7.

9. Stanczyk FZ, Jurow J, Hsing AW. Limitations of direct immunoassays for measuring circulating estradiol levels in postmenopausal women and men in epidemiologic studies. Cancer Epidem Biomar. 2010;81.

10. Ullman EF, Milburn G, Jelesko J, Radika K, Pirio M, Kempe T, et al. Anti-immune complex antibodies enhance affinity and specificity of primary antibodies. Proc Natl Acad Sci. 1993;90:1184-9.

11. Akter S, Vehniäinen M, Spoof L, Nybom S, Meriluoto J, Lamminmäki U. Broad-spectrum noncompetitive immunocomplex immunoassay for cyanobacterial peptide hepatotoxins (microcystins and nodularins). Anal Chem. 2016;88:10080-7.

12. Arola HO, Tullila A, Kiljunen H, Campbell K, Siitari H, Nevanen TK. Specific noncompetitive immunoassay for HT-2 mycotoxin detection. Anal Chem. 2016;88:2446-52.
13. Maruyama H, Sperlagh M, Zaloudik J, Liang S, Mizuki K, Molthoff C, et al. Immunization procedures for anti-idiotypic antibody induction in mice and rats. J Immunol Methods. 2002;264: 121-33.

14. Pulli T, Höyhtyä M, Söderlund H, Takkinen K. One-step homogeneous immunoassay for small analytes. Anal Chem. 2005;77:2637-42.

15. Arola HO, Tullila A, Kiljunen H, Campbell K, Siitari H, Nevanen TK. Specific noncompetitive immunoassay for HT-2 mycotoxin detection. Anal Chem. 2016;88:2446-52.

16. Sambrook J, Fritsch EF, Maniatis T. Molecular cloning: a laboratory manual: Cold spring harbor laboratory press; 1989.

17. Lamminmäki U, Westerlund-Karlsson A, Toivola M, Saviranta P. Modulating the binding properties of an anti-17 $\beta$-estradiol antibody by systematic mutation combinations. Protein Sci. 2003;12: 2549-58.

18. Brockmann E, Akter S, Savukoski T, Huovinen T, Lehmusvuori A, Leivo J, et al. Synthetic single-framework antibody library integrated with rapid affinity maturation by VL shuffling. PEDS. 2011;24: 691-700.

19. Huovinen T, Syrjänpää M, Sanmark H, Brockmann E, Azhayev A, Wang Q, et al. Two ScFv antibody libraries derived from identical VL-VH framework with different binding site designs display distinct binding profiles. PEDS. 2013;26:683-93.

20. Leivo J, Mäkelä J, Rosenberg J, Lamminmäki U. Development of recombinant antibody-based enzyme-linked immunosorbent assay (ELISA) for the detection of skatole. Anal Biochem. 2016;492:27-9.

21. Ketha H, Girtman A, Singh RJ. Estradiol assays-the path ahead. Steroids. 2015;99:39-44.

22. Handelsman DJ, Newman JD, Jimenez M, McLachlan R, Sartorius G, Jones GR. Performance of direct estradiol immunoassays with human male serum samples. Clin Chem. 2014;60:510-7.

23. Kokko T, Kokko L, Lövgren T, Soukka T. Homogeneous noncompetitive immunoassay for $17 \beta$-estradiol based on fluorescence resonance energy transfer. Anal Chem. 2007;79:5935-40.

24. Kuningas K, Ukonaho T, Päkkilä H, Rantanen T, Rosenberg J, Lövgren $T$, et al. Upconversion fluorescence resonance energy transfer in a homogeneous immunoassay for estradiol. Anal Chem. 2006;78:4690-6.

25. Tanaka T, Takeda H, Ueki F, Obata K, Tajima H, Takeyama H, et al. Rapid and sensitive detection of $17 \beta$-estradiol in environmental water using automated immunoassay system with bacterial magnetic particles. J Biotechnol. 2004;108:153-9.

26. Haisenleder DJ, Schoenfelder AH, Marcinko ES, Geddis LM, Marshall JC. Estimation of estradiol in mouse serum samples: evaluation of commercial estradiol immunoassays. Endocrinology. 2011;152:4443-7.

Publisher's note Springer Nature remains neutral with regard to jurisdictional claims in published maps and institutional affiliations. 